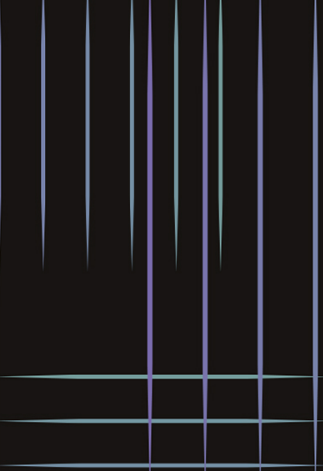

WORKING METHODS

FOR KNOWLEDGE

MANAGEMENT

COMMUNICATING

KNOWLEDGE

DENISE BEDFORD

IRA CHALPHIN

KAREN DIETZ

KARLA PHLYPO 


\section{Communicating Knowledge}




\section{WORKING METHODS FOR KNOWLEDGE MANAGEMENT}

Knowledge Economies and Knowledge Work

Bill Lafayette, Wayne Curtis, Denise Bedford, and Seema Iyer

Knowledge Assets and Knowledge Audits

Pawan Handa, Jean Pagani, and Denise Bedford

Critical Capabilities and Competencies for Knowledge Organizations Juan Cegarra-Navarro, Alexeis Garcia-Perez, Susan Wakabayashi, Denise Bedford, and Margo Thomas

Designing and Tracking Knowledge Management Metrics Alexeis Garcia-Perez, Farah Gheriss, and Denise Bedford

Translating Knowledge Management Visions into Strategies Angel Williams, Monique Ceruti, and Denise Bedford

Assessment Strategies for Knowledge Organizations Dean Testa, Johel Brown-Grant, and Denise Bedford

Learning Organizations

Malva Daniel Reid, Jyldyz Bekbalaeva, Denise Bedford, Alexeis Garcia-Perez, and Dwane Jones

Knowledge Networks

Denise Bedford and Thomas W. Sanchez

\section{Forthcoming}

Communicating Knowledge

Denise Bedford, Ira Chalphin, Karen Dietz, and Karla Phlypo

Organizational Intelligence and Knowledge Analytics

Brian McBreen, John Silson, and Denise Bedford

The Cultures of Knowledge Organizations

Wioleta Kucharska and Denise Bedford

Knowledge Representation and Preservation

Hossein Arvand, Margie Foster, Hugh Graham, and Denise Bedford 


\section{Communicating Knowledge}

BY

\section{DENISE BEDFORD}

Georgetown University, USA

\section{IRA CHALPHIN}

Ira Global School, USA

\section{KAREN DIETZ}

Polaris Associates, Inc. USA

AND

\section{KARLA PHLYPO}

Walden University, USA
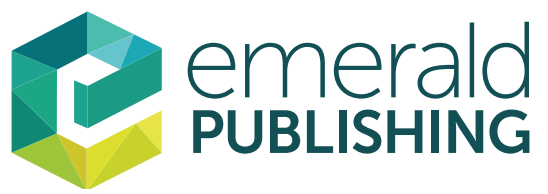

United Kingdom - North America - Japan - India - Malaysia - China 
Emerald Publishing Limited

Howard House, Wagon Lane, Bingley BD16 1WA, UK

First edition 2022

Copyright (C) 2022 Emerald Publishing Limited

Reprints and permissions service

Contact: permissions@emeraldinsight.com

No part of this book may be reproduced, stored in a retrieval system, transmitted in any form or by any means electronic, mechanical, photocopying, recording or otherwise without either the prior written permission of the publisher or a licence permitting restricted copying issued in the UK by The Copyright Licensing Agency and in the USA by The Copyright Clearance Center. Any opinions expressed in the chapters are those of the authors. Whilst Emerald makes every effort to ensure the quality and accuracy of its content, Emerald makes no representation implied or otherwise, as to the chapters' suitability and application and disclaims any warranties, express or implied, to their use.

British Library Cataloguing in Publication Data

A catalogue record for this book is available from the British Library

ISBN: 978-1-80262-104-4 (Print)

ISBN: 978-1-80262-103-7 (Online)

ISBN: 978-1-80262-105-1 (Epub) 


\section{Contents}

Introduction to the Series vii

Preface ix

Section 1: Communicating Knowledge

Chapter 1 The Shifting Landscape of Organizational

Communication 3

Chapter 2 Knowledge Communication in the New World of Work 23

Chapter 3 Knowledge Capital and Knowledge Mobilization 37

Chapter 4 Designing Management Communications for the Knowledge Economy 49

Section 2: Communicating Knowledge Assets

Chapter 5 Communicating Human Capital 67

Chapter 6 Communicating Structural Capital 93

Chapter 7 Communicating Relational Capital 123

Section 3: Key Issues in Knowledge Communications

Chapter 8 Discernment as a Management Issue 143

Chapter 9 Listening as a Management Issue 155 
vi Contents

Chapter 10 Facilitation as a Management Issue 171

Chapter 11 Decision-making as a Management Issue 179

Chapter 12 Team Building as a Management Issue 193

Section 4: Building Communications Competencies and Capacity

Chapter 13 Building Communications Competencies 205

$\begin{array}{lll}\text { Chapter } 14 & \text { Building Communications Capacity } 217\end{array}$

Appendix. Pulling it all Together 223

$\begin{array}{ll}\text { Index } & 237\end{array}$ 


\section{Introduction to the Series - Working Methods in Knowledge Management}

Knowledge sciences as a discipline have a rich and diverse history dating back to the 1950s. In the past 70 years, the discipline has drawn theory and practice from economics, engineering, communications, learning sciences, technology, information sciences, psychology, social sciences, and business and organization management. To craft this discipline, we have developed our own language and terminologies, established our own peer reviewed journals and built a rich research foundation, created a gray literature and established a series of networks and conferences. Over the decades there have been many knowledge management education programs, but there is no consistent curriculum and few have sustained. It has been challenging for new practitioners to gain an understanding of the field. And, while the practice of knowledge management is growing around the world it has not yet achieved the expected organizational stature. For knowledge management to rise to the stature of other business functions and operations, it must be able to speak the language of business, align with and support the way the organization works.

This series is designed for business and knowledge management practitioners. Working Methods in Knowledge Management is a multi-year and multi-volume series designed to address each and all of the methods required to establish and sustain an organization-wide knowledge management function. The goal of the series is to provide a business perspective of each topic. Each book begins by grounding the method in the business context - then translates established business models and methods to a knowledge management context. It is often the case that this translation expands and extends the business model and method.

The knowledge management literature is rich with introductory handbooks, guidebooks, cookbooks, toolkits, and practical introductions. This literature is an important starting point for anyone new to the discipline. We recommend any and all of these books as a way to build a fundamental understanding of the scope and coverage of the field. These texts will provide a good 10-20 pages introduction to all of the key issues you need to be aware of as you embark on a new career in the field or have been assigned a new knowledge management role or responsibility. Once you have that grounding, though, we recommend that you look to the Working Methods in Knowledge Management texts as an intermediate source for understanding "What comes next? What now?" 
Just as this series is not intended as a starting point for the field, neither is it an ending point. Each text is designed to support practical application, and to foster a broader discussion of practice. It is through practical application and extended discussion that we will advance theory and research. The editors anticipate that as practice expands, there will be a need to update the texts - based on what we are learning. Furthermore, the editors hope the texts are written in a way that allows business managers to extend their work to include knowledge management functions and assets. We will learn most from expanding the discussion beyond our core community.

\section{Joint Enterprise, Mutual Engagement, and a Shared Repertoire}

From the outset, the publisher and the editors have established a new and different approach to designing and writing the books. Each text is supported by a team of authors who represent multiple and diverse views of the topic. Each team includes academics, practitioners, and thought leaders. Every author has grappled with the topic in a real world context. Every author sees the topic differently today than they did when the project began. Over the course of several months, through weekly virtual discussions, the scope and coverage were defined. Through mutual engagement and open sharing, each team developed a joint enterprise and commitment to the topic that is enduring. Every author learned through the discussion and writing process. Each project has resulted in a new shared repertoire. We practiced knowledge management to write about knowledge management. We "ate our own dog food."

\section{Acknowledgments of Early Support}

The series is a massive effort. If there is value in the series much of the credit must go to two individuals - Dr Elias Carayannis, George Washington University, and Dr Manlio Del Giudice, University of Rome. It was Dr Carayannis who first encouraged us to develop a proposal for Emerald Publishers. Of course, this encouragement was just the most recent form of support from Dr Carayannis. $\mathrm{He}$ has been a mentor and coach for close to 20 years. It was Dr Carayannis who first taught me the importance of aligning knowledge management with business administration and organizational management. Dr Del Giudice has been generous with his guidance - particularly in setting a high standard for any and all knowledge management research and practice. We are grateful to him for his careful review and critique of our initial proposal. His patience and thoughtful coaching of colleagues is rare in any field. The field will reach its full potential as long as we have teachers and editors like Dr Del Giudice.

Dr Denise Bedford, Georgetown University

Dr Alexeis Garcia-Perez, Coventry University 


\section{Preface}

\section{Overview of the Subject Matter}

The communication of knowledge is a core concept in the field of knowledge management. The knowledge management literature devotes extensive time and attention to knowledge communication. Unfortunately, this coverage is largely superficial and fragmented. It is referred to as knowledge exchange, sharing, transfer, and translation. There is no standard definition of what we mean by this act of communication. There is no foundational conceptual model. Where the process begins, where it ends, the essential mechanics of the components are largely undefined. It represents a significant gap in the literature for a critical discipline.

Communicating knowledge is an essential new role and responsibility of business managers in the twenty-first century knowledge economy. Knowledge capital is the primary source of wealth and the key source of productivity in the knowledge economy. Stockpiling and storing knowledge diminishes its value. It is only through circulation and uses that our knowledge capital realizes its business value. Ensuring effective circulation and use translates to everyday knowledge communication. It does not mean simply broadcasting information or making information accessible; it means ensuring that every workforce member knows what they know and can effectively communicate that to others in the business environment.

The current treatment in the knowledge management literature also fails to acknowledge the essential role of communication in these core processes. And, the communication literature tends to focus on traditional, formal roles, and responsibilities, that is, strategic communications, public relations, and internal organization communications. The authors also suggest a general gap in the communications literature about interpersonal communication skills and competencies. The authors expand the treatment of interpersonal communication skills to suggest ways to fill this gap.

\section{Where the Topic Fits in the World Today}

This text addresses essential management practices in the twenty-first century knowledge economy. It speaks to the change that every organization is experiencing as they transition from an industrial to a knowledge organization. Our experiences with the COVID-19 pandemic have heightened our awareness of our communications practices in the past year. Our communications norms and 
behaviors have been challenged at every level. We are in the process of redefining how we communicate when we communicate, with whom we communicate, and what we communicate. Communication competencies are no longer desirable qualities in managers; they are essential qualities. The authors hope this text contributes to the revitalized discussions about organizational communications in the world today.

\section{Where the Book Fits in the Literature Today}

Because the topic is transdisciplinary, we will speak to where it fits in each discipline. In the knowledge management literature, this book speaks to core concepts. It is intended to provide a more profound knowledge-sharing treatment and exchange and communicate the eight types of knowledge capital. In the business management literature, this book addresses new management competencies. The authors intend to reframe the traditional conception of organizational communications for managers who must take greater responsibility for creating and leveraging business knowledge. In the economics literature, this text addresses essential economic transactions involving knowledge capital. The fundamental nature of knowledge requires that we see these economic transactions and forms of communication. This text is an addition to the communications literature in that it extends the treatment of interpersonal communications attributes and competencies for today's managers. It speaks to new and more extensive competencies that are essential for leveraging business knowledge. Finally, this text has a place in the human resources literature in that it promotes the treatment of traditional "soft" and subjective skills to essential skills. The role of human resource professionals in achieving this transition is essential.

\section{The Intended Audience for this Book}

This text is intended for business managers working at all levels, knowledge management practitioners, and scholars. This text is intended for communications professionals, practitioners, and consultants. The authors also hope that human resource professionals will gains insights into evolving competencies.

\section{Structure of the Book}

The book is organized into four sections and 17 chapters. Section 1 focuses on the role of knowledge in the knowledge economy, the economic properties of knowledge, and the role of managers in facilitating the communication of knowledge. This section is comprised of four chapters. Section 2 introduces the reader to communication processes and elements and their relationship to knowledge flows. This section is comprised of four chapters. Section 3 guides the reader by reviewing the factors that may influence communication and comprises five chapters. Section 4 focuses on sustaining an organization's capacity to communicate knowledge through capabilities and competencies. Four chapters support this section. 


\section{Chapter Summaries}

The summaries of all 16 chapters are provided below. The reader will also find extensive references to literature, thought leaders, and practitioners on that topic.

Chapter 1 explains that the value of knowledge is realized only when it circulates. Knowledge mobility is a core business operation of every organization in the twenty-first century. Organizational communications have evolved over the past century as a discipline communication emerged as a support function and capability for the new science of management. From a business management perspective, communications have been treated as a generalized "soft skill." Professional or specialized communications responsibilities are assigned to communications officers, public relations team, and corporate communication specialists. Traditionally, communication has been about crafting and controlling the message reflecting an industrial and engineered economy and society. Communication is now everyone's role and everyone's responsibility. The need to leverage knowledge capital in the knowledge economy means that every organization needs to pay more attention to communications as a critical management competency.

Chapter 2 explains how the world of work is changing in the knowledge economy. The fundamental change is from one command and control to one of engagement and participation. The new world of work presumes that the knowledge of every individual has value to the organization's success. The changing nature of work means a shift from managing processes and job classifications to managing business capabilities and workforce competencies. These authors suggest that in this new environment, managers have a more complex workforce to "manage" and an increasingly complex and dynamic work environment. To navigate this change, managers must expand their interpersonal communication skills to ensure that the knowledge of every employee realizes its total business value. This chapter presents a series of critical questions to guide managers in developing twenty-first century communication roles and responsibilities.

Chapter 3 explains how knowledge and its effective business use are critical success factors for any organization in the knowledge economy. Knowledge is what fuels our twenty-first century economic systems. Knowledge has always been part of our economic systems, but recent events and advances have made it more visible and accessible. The authors make the case that to succeed in the knowledge economy, our cultivation and use of knowledge assets cannot be accidental or secondary. This chapter reminds us that organizations must approach communication as an essential business capability. Communicating knowledge requires both an awareness of knowledge assets and the ability to tailor a communication strategy to ensure its effective transformation and use. Business communication happens while we are working - each organization and each work unit must design an effective and relevant transformation strategy.

In Chapter 4, the authors explain the play pivotal role leaders and managers play in defining a unit and team's work environment and culture. In this chapter, we make the case that the twenty-first century knowledge organization depends on the effective mobilization and exchange of business-relevant knowledge. It is the primary responsibility of twenty-first century managers to understand the 
traditional role and methods of public relations, strategic and internal communications and cultivate their interpersonal communications. Additionally, managers must be aware of the value of knowledge capital; they must be aware of the knowledge stocks of their teams and the knowledge that is essential to accomplishing the business goal. The authors make the case that a manager must be competent in designing each communication to ensure effective knowledge flows. This chapter reviews the essential communication skills and competencies, and personal communication attributes that a successful twenty-first century manager requires.

In Chapter 5, the authors offer insights and critical questions to help advance ideas about human capital forms of knowledge. An organization's human capital is represented by tacit knowledge, skills and competencies, and people's personalities and personal attributes. In this chapter, the authors examine the three types of human capital and consider how communication contributes to growing and leveraging that knowledge. The authors strive to fill a gap in exchanging exchange for human capital in knowledge management literature. Communicating human capital is grounded in understanding what it is, how each type of human capital asset behaves, and the challenges we must address in facilitating that communication. This chapter provides the reader with a definition of each type of human capital, explains how it develops and is communicated, and identifies some fundamental challenges.

In Chapter 6, the authors explain that structural capital is critical to developing organization-wide knowledge capabilities. While structural capital is associated with groups, communities, and the organization, it also has implications for individuals. Through their individual and collective activities, individuals contribute to the creation of structural capital. This chapter provides an extended discussion of how individuals and organizations can grow their explicit knowledge, procedural knowledge, and organizational culture attributes. This chapter examines these issues in the context of learning cultures and learning spheres. These issues include determining sources, opportunities and challenges, risks, and the inherent interrelatedness of human capital, structural capital, and relational capital assets. The authors explain how we apply the design process to structural capital.

In chapter 7, the authors explain the critical role that relational capital plays in knowledge flows and transfers. They also explain why networks and relationships are essential to any attempt to grow human or structural capital. Additionally, network relationships are critical to developing and establishing a reputation. This chapter provides an extended discussion of how individuals and organizations can grow their networks, network relationships, and reputations. The chapter also examines these issues in the context of learning cultures and learning spheres. These issues include determining sources, opportunities and challenges, risks, and the inherent interrelatedness of human capital, structural capital, and relational capital assets.

Chapter 8 explains what discernment is and why it matters for managers. The authors cover the three areas of discernment critical to a manager's success: conversational intelligence discernment, narrative intelligence discernment, 
and organizational communication discernment. The discernment process is described, and the seven kinds of knowledge and discernment skills to build. This chapter provides a foundation upon which to build additional skills.

Chapter 9 explains the consequences of poor communication to both an organization and individual managers. The authors also address the significance of ethical communication and how to communicate honorably. The chapter also helps the reader understand how to be more self-reflective. The importance of trust and how to build and maintain it are described. The authors also explain the neuroscience of narratives, and this helps managers communicate better. This chapter also helps the reader to understand their communication style. Most important, though, this chapter explains the power and process of better listening.

In chapter 10, the authors provide a definition and characterization of facilitation. The authors explain the role of intention and the importance of choosing a communication position. This chapter raises the reader's awareness of leveraging facilitation and feedback to support high-performing teams in the workplace. Additionally, the authors define and describe the vital competency of appreciative inquiry. Finally, the authors highlight the importance of providing feedback as a management competency.

In Chapter 11, the authors define decision-making and explain the role of decision-making in knowledge flows. Intuitive reasoning is also described. The authors also highlight the importance of managers understanding the types of decisions they make and understanding their decision-making styles. An overview of decision-making factors is presented, and the role they play in effective decision-making is explained. Finally, the chapter considers what it means to communicate a decision effectively.

In Chapter 12, the authors define and characterize high-performance teams. The role that high-performance teams play in achieving effective knowledge flows is explained. The role that knowledge capital plays in high-performance building teams is discussed. The importance of feedback to high-performance teams is highlighted. Finally, the role of trust in achieving high-performance teams is discussed.

Chapter 13 focuses on the types of roles, responsibilities, and competencies essential to knowledge communications. The authors draw upon earlier series authors' important work (Garcia-Perez et al., 2019) to define competencies. The authors define four categories of communications competencies, including those suited to strategic roles, those that support specialized communications work, those that support embedded communications roles, and universal competencies that apply to everyone.

Chapter 14 explains how organizations can build communications capabilities into their everyday working environments. The definition of capacity building builds upon the organizational management and the strategic workforce development literature. This chapter also derives essential guidance from another series focused on critical capabilities and capacity building. The authors highlight the role of a robust communications culture in building communications capacity. Capacity building is achieved through short- and long-term efforts. This chapter also highlights the importance of balancing capacity building across everyday business operations and specialized communications functions. 


\section{How this Book Impacts the Field}

The authors intend to provide a holistic picture of core processes that comprise knowledge exchange. Authors intend to help business managers to understand what they can do to achieve more effective knowledge sharing and flows within their work operations. We hope to provide a foundation upon which to ground and grow the discussion of knowledge exchange and distinguish those exchanges by type of knowledge asset. We attempt to build on the solid foundation established by Bontis and Andriessen in their characterization of knowledge capital. The authors hope the practical coverage of the issues will encourage more effective knowledge flows within work operations.

The book aims to create a new dialog among knowledge management professionals and practitioners, business managers, and communications professionals.

We hope the practical treatment will encourage those in the business community to increase their awareness of their communication styles and cultivate them to increase knowledge flows.

Until this dialog begins, each area of practice will operate in isolation. The risk is that knowledge management processes will be sub-optimized without input from communications professionals. Until this dialog begins, each practice area will focus on the part of the solution, most likely generalized communication or exchange. Until this dialog begins, no one area of practice will effectively address the challenge. The authors hope this book will be a catalyst for that dialog.

\section{Notes from the Authors}

The year this text was written was a year when there were significant disruptions to our communications processes. The COVID-19 pandemic changed our work environments, shifted our primary and secondary networks, and tended to highlight the individual in their "home" environment. Our attributes and communications styles were exposed. It presented both challenges and opportunities. The challenges arose in how the team was able to work together, shifting from periodic in-person contacts to entirely virtual and often asynchronous communications. It forced each of us to take stock of our communication styles, and to assess our abilities to collaborate. Each author brought a different expertise to the task, representing different fields. The multidisciplinary nature of the team provided rich opportunities for us to each expand our knowledge based on joint learning and authorship. In this book, perhaps more than others in the series, we let the individual voices and styles of the authors come through in the text. We hope you enjoy the richness of the text! 